\title{
Cardiac catheter complications related to left main stem disease
}

\author{
J D Kovac, D P de Bono
}

\begin{abstract}
Objective-To examine the incidence and outcome of cardiac catheter complications related to left main coronary artery disease or damage using the CECCC (Confidential Enquiry into Cardiac Catheter Complications) database.

Setting-Coordinating centre for national database.

Design-Retrospective analysis of reports to a national multicentre database for cardiac catheter complications. Complications involving the left main coronary artery were flagged at entry. Where necessary additional information was sought from participating centres. 112921 procedures were registered, 12849 of which were coronary angioplasties and the remainder diagnostic studies.
\end{abstract}

Results-The total number of cases for which complications were recorded was $993(0 \cdot 88 \%)$. In $61(6 \cdot 14 \%)$ of the 993 cases complications were associated with left main coronary disease or damage. In 57 $(93 \%)$ of these 61 cases complications were major, necessitating resuscitation or immediate coronary bypass grafting. Ten patients $(16 \%)$ died in the catheter laboratory, a further 9 (15\%) within 24 hours, and a total of 23 patients $(38 \%)$ died within one month of the procedure. Left main stem related complications account for $17 \%$ of total mortality in the CECCC database. Urgent coronary bypass grafting was attempted in 42 patients, of whom 31 were alive at one month. In all of the six reported PTCA-related complications the cause was traumatic damage to the left main coronary artery. Operators of all grades of seniority experienced complications in similar proportions.

Conclusions-The risk of a complication relating to the left main stem is relatively low, but when such complications occur they tend to be life-threatening and contribute a fifth of total catheter-related mortality. In the absence of a widely available non-invasive investigation with good predictive value for left main stem disease, the best safeguard is careful technique. Patients who do develop complications should have emergency coronary bypass grafting.
(Heart 1996;76:76-78)

Keywords: cardiac catheter; complication; left main stem

Left main coronary artery stenosis is well recognised as having a poor prognosis with medical management, and such patients benefit from early surgical intervention..$^{1-3}$ Although severe coronary disease may be suspected from the severity of symptoms or the early appearance of ischaemia on non-invasive testing, there is currently no reliable non-invasive method for predicting left main stenosis, and it is definitively diagnosed only by coronary angiography. ${ }^{45}$ There have been numerous anecdotal accounts of complications related to coronary angiography in patients with left main coronary stenosis, and it has been identified as a major risk factor for increased periprocedure mortality. ${ }^{6}$

We have used the UK CECCC database ${ }^{7}$ in an attempt to assess the frequency, type, and outcome of complications related to the left main stem in patients undergoing diagnostic or interventional cardiology.

\section{Methods}

The UK Confidential Enquiry into Cardiac Catheter Complications (CECCC) is a voluntary scheme in which participating centres provide monthly information about the numbers of procedures (diagnostic catheters and angioplasties) performed in their own unit, and notify the coordinating centre of any complications, defined as "any unexpected event which jeopardises a patient's life or prolongs their hospital stay". Units participating in CECCC range from major centres investigating $>2000$ patients per year to single-operator units investigating 100-150 patients annually. Complication reports include a brief freehand description of the incident which is recorded verbatim in the CECCC database. During the period of this study all reports were screened by one of us (D de B) at the time of entry, and those mentioning a left main lesion or damage were flagged for future identification. Where necessary, centres were asked to provide additional information about outcome.
Professor D P de Bono,

Clinical Science Wing LE3 9QP.

Accepted for publication 24 January 1996
Division of Cardiology, Medicine, U

J D Kovac

D P de Bono 
Results

Between September 1990 and the end of December 1994 the CECCC database logged 112921 procedures, of which 12849 were coronary angioplasties and the remainder diagnostic procedures. 993 cases with complications were reported, and in 61 cases the report identified pre-existing or iatrogenic left main coronary artery lesions as contributing factors. 55 of these left main stem-related cases related to diagnostic angiography and six to coronary angioplasty, In 49 of the 61 cases with left main stem related complications $(80 \%)$ these occurred during routine procedures and in 12/61 (20\%) during urgent investigation of unstable cases. In 44 of the 61 cases (72\%) complications occurred during or immediately after the procedure while the patient was still in the catheter laboratory, and $17(28 \%)$ after return to a ward or recovery area. In 57 cases (93\%) complications were defined as "serious" in that they involved cardiopulmonary resuscitation and/or were followed by emergency surgery. Cardiac arrest was reported in 33 of the 61 cases (54\%)

Twenty three patients $(38 \%)$ died within one month of the procedure, of whom 10 $(16 \%)$ died in the catheter laboratory and a further nine (total $31 \%$ ) within 24 hours of the procedure. During the same period a total of 112 procedure-related deaths was reported to the CECCC database. Emergency coronary bypass grafting was attempted in 42 cases $(69 \%)$, of whom 34 patients survived 24 hours and 31 were alive at one month. These data are summarised in the table.

In 20 of the cases $(33 \%)$ the first operator was a consultant, in $16(26 \%)$ a senior registrar, in $20(33 \%)$ a registrar, and in $5(8 \%)$ another grade of operator.

All six of the PTCA patients had iatrogenic dissection of a non-stenotic left main coronary artery. Of the remainder, $49 / 55$ had a preexisting, proximal left main stenosis, $2 / 55$ had an apparently normal left main at the start of the procedure, and in four the pre-catheter state of the left main could not be determined. Judkins guiding catheters were used for $5 / 6$ PTCA cases, and a left Amplatz catheter for one. 5/55 of the diagnostic catheter cases used the brachial approach with Castillo or Sones catheters, in the remainder a femoral approach was used. The CECCC database does not record the approach used in uncomplicated

\section{Left main stem related complications}

Total number of procedures logged (9/90 to $12 / 94)$ of which:

$$
\text { Diagno }
$$

Total number of complications logged

Total num

Left main related

Of 61 patients with left main related complications.

Of 61 patients with left

Symptoms presenting in catheter laboratory

Died in catheter laboratory:

within 24 hours

within 24 hours

Bypass grafting attempted

Of 42 patients in whom bypass grafting was attempted:

24 hour survival

30 day survival cases, so it is not possible to determine whether or not complications were more frequent with a brachial approach or with a particular type of catheter.

\section{Discussion}

The CECCC database does not collect information about the severity and distribution of coronary disease. Retrospective surveys have given estimates for the prevalence of left main stem stenosis in patients undergoing diagnostic angiography ranging from 0.7 to $5.6 \% .^{25}$ The tendency in the United Kingdom to reserve coronary angiography for more severely symptomatic patients probably means that the prevalence in our population is closer to $5 \% .{ }^{9}$ If this is correct then the estimated risk of a catheter-related complication in patients with left main stenosis is approximately $1.05 \%$, which is only marginally greater than the overall complication rate of $0.87 \%$. On the other hand, left main stem related complications are much more likely to be serious, and they accounted for nearly a fifth of overall catheter related mortality.

In the patients who underwent emergency coronary bypass grafting, one month survival was $74 \%$. There was a trend towards a better outcome in those who went directly from the catheter laboratory to surgery compared with those who developed symptoms for the first time in the recovery area. We do not have adequate data to compare outcome in units with on-site versus off-site surgical cover. In the worst case scenario, if all 42 patients who underwent coronary bypass grafting had died, the overall CECCC database mortality would have increased from $0 \cdot 099 \%$ to $0 \cdot 136 \%$.

In the present study complications involving the left main stem occurring during diagnostic catheterisation were very often associated with a pre-existing proximal left main stenosis. At present the existence of such lesions cannot be predicted with any accuracy by non-invasive means, although there is some evidence that the prevalence of left main stem disease is higher in older age groups, ${ }^{89}$ in middle aged women ${ }^{1011}$ who present with typical anginal symptoms, or in the East Asian population. ${ }^{12}$ Ostial left main stem stenosis has been reported in patients with Takayasu disease, syphilitic aortitis, and aortic valve disease $\mathrm{e}^{13-15}$ but none of the patients in the present study appeared to have these diseases. The predictive value of clinical markers is also low, although there is some evidence from retrospective studies that patients presenting with severe anginal symptoms (NYHA III), and low exercise tolerance ${ }^{16-19}$ are more likely to have left main stem disease. Despite encouraging initial reports, neither transthoracic nor transoesophageal ultrasound imaging ${ }^{20-22}$ nor magnetic resonance imaging ${ }^{23-25}$ can yet be regarded as routine techniques for non-invasive detection of left main stem disease.

There is no evidence from the present study of any association between risk of a left-main related complication and size of catheter, catheter technique, or type of contrast agent, 
but this might have been due to the limitations of the database. Nor was there any obvious relation with operator experience, though it is likely that cases perceived as being at increased risk will have been allocated to more experienced operators.

The traditional management of a severe proximal left main stenosis, namely a limited angiographic study with a minimum number of coronary views, followed by urgent bypass grafting, remains appropriate. If there is any chest pain or haemodynamic disturbance during or after the study emergency surgery is essential. Despite all precautions, the first intimation of trouble is frequently catastrophic haemodynamic deterioration. Balloon pumping is often ineffective because of arrhythmia; extracorporeal assist devices would be appropriate but are seldom available. Reports of successful emergency left main stem angioplasty and stenting are as yet only anecdotal ${ }^{26}{ }^{27}$ and this treatment should perhaps be used only as a bridge towards immediate coronary bypass grafting.

\section{CONCLUSIONS}

The risk of a complication related to the left main stem is relatively low, but when such complications do occur, they tend to be serious, life-threatening and contribute a fifth of total catheter related mortality. In the absence of a widely available non-invasive investigation with good predictive value for left main stem disease, the best safeguard against left main stem related problems is careful technique. In patients with unexpected proximal left main stenosis, views should be limited to those that are absolutely essential and in the case of complications patients should have emergency coronary bypass grafting.

1 Janek B, Malek I, Ouhrabkova R, Firt P, Fridl P, Horak J, et al. Left main coronary artery stenosis, Cor et Vasa 1992; 34:123-4.

2 Tonz M, Laske A, Niederhauser U, Kaufmann U, Pasic M, von Segesser LK, et al. Main coronary artery stenosis: a continuous

3 Vigneswaran WT, Sapsford RN, Stanbridge RD. Disease of the left main coronary artery: early surgical results and their association with carotid artery stenosis. Br Heart $\mathcal{f}$ their association

4 Bernardes L, Patricio L, Cequier A, Mauri J, Sala J, Esplugas E. Stenosis of the common trunk with and without ostium involvement: clinical and angiographic characteristics. Rev Port Cardiol 1991;10:221-6.

5 Topaz O, Warner M, Lanter P, Sofer A, Burns C, Di Sciascio $\mathrm{C}, e t$ al. Isolated left main coronary artery stenosis: angiographic, hemodynamic and clinical findings in 16 patients. Am Heart $\mathcal{F}$ 1991;122:1308-14.

6 Boehrer JD, Lange RA, Willard JE, Hillis, LD. Markedly increased periprocedure mortality of cardiac catheterization in patients with severe narrowing of the left main coronary artery. Am $\mathcal{C}$ Cardiol 1992;70:1388-90.

7 de Bono DP. Complications of diagnostic cardiac catheterisation: results from 34041 patients in the United Kingdom confidential enquiry into cardiac catheter complication. Br Heart $\mathcal{f}$ 1993;70:297-300.

8 Yanagi $K$, Toyama $M$, Tanabe $H$, Ozaki S, Kawase I. Morbidity and mortality of coronary artery bypass surgery in patients 75 year of age or older. $\mathcal{F} \mathrm{fpn}$ Ass Thorac Surg 1992;40:11, 1978-1986

9 Elder AT, Shaw TR, Turnbull CM, Starkey IR. Elderly and younger patients selected to undergo coronary and younger patients selected to

10 Yamanaka $P$, Hobbs RE. Solitary ostial coronary artery stenosis. Fpn Circ F 1993;57:404-10.

11 Okayama H, Watanabe K, Abe M, Matsuoka H, Sumimoto T, Sekiya $M$. A case of middle aged women with isolated left ostial coronary stenosis. Resp Circ with isolated 6 .

12 Koh KK, Hwang HK, Kim PG, Lee SH, Cho SK, Kim SS, et al. Isolated left main coronary ostial stenosis in Oriental people: operative, histopathologic and clinical findings in six patients. $f$ Am Coll Cardiol 1993;21: 369-73

13 Seguchi M, Hino Y, Aiba S, Yasukochi S, Momma V, Takao A, et al. Ostial stenosis of the left coronary artery as a sole clinical manifestation of Takayasu arteritis, a possible cause of unexpected sudden death, Heart Vessels 1990;5:188-91.

14 Iga K, Gohma I, Hori K. Regression of the left main trunk lesion by steroid administration in Takayasu's aortitis. Chest 1991;99:508-10.

15 Nakashima H, Takahara A, Yoshioka M, Suzuki S, Mori $\mathrm{HJ}$, Oku Y. A case of left coronary ostial obstruction due to syphilitic aortitis. Resp Circ 1991;39:831-5.

16 Hubbard BL, Gibbons RJ, Lapeyre AC 3rd, Zinsmeister $\mathrm{AR}$, Clements IP. Identification of severe coronary artery disease using simple clinical parameters. Arch Intern Med 1992;152:309-12.

17 Aursnes I, Benestad AM, Sivertssen S, Skjaeggestad O, Gronseth $\mathrm{K}$. Degree of coronary artery disease predicted by exercise testing. F Int Med 1991;229:325-30.

18 Miranda CP, Lehmann KG, Froelicher VF. Correlation between resting ST segment depression, exercise testing, coronary angiography and long term prognosis. Am Heart f 1991;122:1617-28.

19 Gibbons RJ, Fyke FE 3rd, Brown ML, Lapeyre AC 3rd, Zinsmeister AR, Clements IP. Comparison of exercise performance in left main and three vessel coronary artery disease. Cathet Cardiovasc Diagn 1991;22:14-20.

20 Memmola C, Iliceto S, Rizzon P. Detection of proximal stenosis of left coronary artery by digital transesophageal stenosis of left coronary artery by digital transesophageal Am Soc Echocardiogr 1993;6:149-57.

21 Yamagishi M, Yasu T, Ohara K, Kuro M, Miyatake K Detection of coronary blood flow associated with left main coronary artery stenosis by transesophageal main coronary artery stenosis by transesophageal Doppler color

22 Nishimura RA, Higano ST, Holmes DR Jr. Use of intracoronary ultrasound imaging for assessing left main coronary artery disease. Mayo Clin Proc 1993;68:134-40.

23 Duerinckx AJ, Urman MK. Two dimensional coronary MR angiography: analysis of initial clinical results. Radiology 1994;193:731-8.

24 Paschal CB, Haacke EM, Adler LP. Three dimensional MR imaging of the coronary arteries: preliminary clinical experience. $\mathcal{F}$ Magn Reson Imaging 1993;3:491-500.

25 Bogaert J, Duerinckx AJ, Baert AL. Coronary MR angiography: a review. 7 Belg Radiol 1994;77:255-61.

26 Garcia Robles JA, Garcia E, Rico M, Esteban E, Perez de Prado A, Delcan IL. Emergency coronary stenting for acute occlusive dissection of the left main coronary artery. Cathet Cardiovasc Diagn 1993;30:227-9.

27 Sathe S, Sebastian M, Vohra J, Valentine P. Bail out stenting for left main coronary artery occlusion following diagnostic angiography. Cathet Cardiovasc Diagn 1994;31: 70-2.

\section{Appendix}

Centres participating in CECCC at 31 December 1994:

Glenfield General Hospital, Leicester; Wythenshawe Hospital, Manchester; St Georges Hospital, London; Kings College Hospital, London; John Radcliffe Hospital, Oxford; BUPA Hospital, Leicester; The London Chest Hospital; Norfolk and Norwich Hospital; Mayday University Hospital, London; The Royal London Hospital; Victoria Hospital, Blackpool; Cardiothoracic Centre, Broadgreen Hospital, Liverpool; Dudley Road Hospital, Birmingham; Maidstone Hospital; Queens Medical Centre, Nottingham; St Bartholomew's Hospital, London; Queen Elizabeth Hospital, Birmingham; University Hospital of Wales, Cardiff; Leeds General Infirmary; Papworth Hospital, Huntingdon; Hospital for Sick Children, Great Ormond Street, London; Royal Postgraduate Medical School, Hammersmith Hospital, London; Westminster Hospital, London; Edinburgh Royal Infirmary; Bristol Children's Hospital; Airedale Hospital, Keighley; Conquest Hospital, St Leonards on Sea; North Staffs Royal Infirmary; York District Hospital; South Cleveland Hospital; Derriford Hospital; St Mary's Hospital, London; Torbay Hospital; Royal United Hospital, Bath. 